\title{
The Relationship Between the Mid-Point and Most-Prominent Point on the Labial Curve of Upper Anterior Teeth
}

\author{
R.N. Smith*, A.H. Brook and M. Karmo
}

Dental Sciences, University of Liverpool, UK

\begin{abstract}
Objectives: This study investigates coincidence of the most-prominent point and the mid-point on upper anterior teeth in relation to the use of straight-wire appliances.

Materials and Methods: Alginate impressions of the upper jaw were obtained from forty Caucasian patients. Impressions were cast using hard dental stone. The teeth on each upper study model (canine to canine) were marked along the facial axis of the clinical crown (FACC line) then separated using a very thin diamond disc. Each tooth was mounted on a glass slide using sticky wax and cut into two halves down this FACC line. Images were acquired of the sections and a straight line connecting the gingival margin and the incisal edge was drawn on the flat cut surfaces (now the proximal crosssectional view). From this line, perpendicular lines were drawn at the mid-point and most prominent point to the labial curve. Coincidence rate was calculated or whether the most prominent point was gingival or incisal to the mid-point.
\end{abstract}

Results: Approximately $80 \%$ of upper central incisors had coincident mid- and most-prominent points. Upper lateral incisors and canine teeth had approximately $50 \%$ coincidence. The vast majority of cases without coincidence showed the most-prominent point incisal to the mid-point for all tooth kinds with just 5\% or less gingival.

Conclusions: The high proportions of non-coincident examples found suggest that clinicians should be aware of individual variation and that this may possibly effect $3^{\text {rd }}$ order alignment.

Keywords: Straight wire appliances, Morphology, Mid- and most prominent points, Image analysis.

\section{INTRODUCTION}

Modern orthodontics has been described as the creation of the finest occlusal relationship within the framework of acceptable facial aesthetics and stability of occlusal result [1]. This requires positioning the crown of each individual tooth in its appropriate position for optimum function and appearance. Straight-wire appliances were designed to reduce or eliminate the need for placing bends in fully engaged straight arch wires. Andrews [2] studied the average torque angles, rotation angles, height and depth of each facial surface of each tooth type from untreated and treated patients having excellent occlusion. He found that when the brackets are precisely positioned at the midpoint of the facial axis and aligned with the facial axis, they collectively become the appliance providing specific tip, torque, rotation angle, height and depth position for each tooth. Limitations have been found in the effectiveness of this bracket system due to several factors, the most important of which is inaccurate bracket positioning [3]. This inaccuracy can only partly be blamed on clinician error as positioning the brackets on the mid-point should ideally be the same location as the mostprominent point [2] to ensure the desired torque effects and tooth movement. These points, however, do not always coincide and in fact may vary around each other to a large degree.

*Address correspondence to this author at the Dental Sciences, University of Liverpool, UK; Tel 0151 7065118; Fax 0151 7065239;

E-mail: r.n.smith@ liverpool.ac.uk
This study was conducted to evaluate the coincidence rate of the mid- and most-prominent points on the labial surface of upper central and lateral incisors and upper canines and possible implications when using straight wire appliances.

\section{METHOD}

One hundred and fifty patients presenting for treatment in the Orthodontic Department, School of Clinical Dentistry, Sheffield, UK were examined by one Orthodontist. Each patient file contained a medical questionnaire signed by the patient's guardian, along with a written examination sheet signed by an orthodontic consultant indicating the level of the patient's oral hygiene, general records, $\mathrm{x}$-ray records and occlusion type. Any missing teeth, supernumerary teeth or other abnormalities were also noted. From the one hundred and fifty patients, forty fulfilled the following inclusion/ exclusion criteria: all patients were of Caucasian origin, aged between 13-16 years, had fully erupted upper incisor and canine teeth, good oral hygiene, with a healthy gingival margin around the upper anterior teeth, intact teeth e.g. no restorations, attrition or abrasion, mild or no crowding in the anterior region and the cases did not exhibit any abnormality of tooth number, form or structure and no medical or other health problems. This sample size exceeded others used within the department for morphology studies after statistical advice and calculation. The authors suggest that further calculations may be required when considering cases other than those with class 1 relationships. 


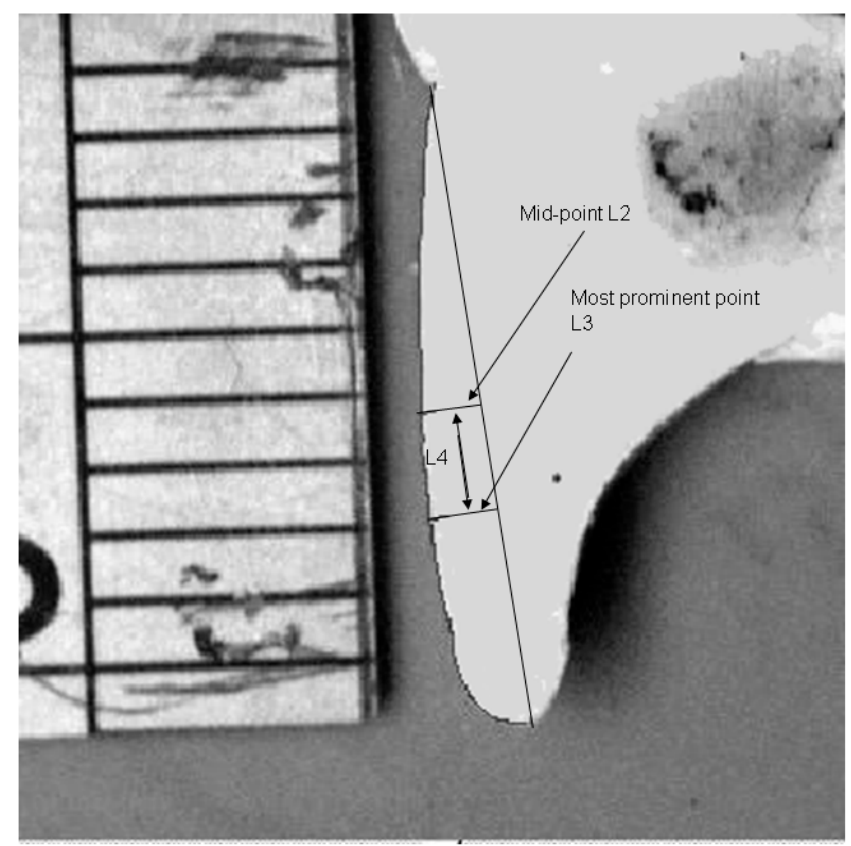

Fig. (1). Proximal section of a central incisor displaying the variables.

The age of the sample was limited to between 13 and 16 years old to ensure that the teeth of interest were fully erupted but not worn. There were no restorations of their crowns.

An alginate impression (Alginoplast, Bayer) was taken of the upper jaw of the forty patients using hard dental stone (Kaffir D, British Gypsum. All the study models were duplicated using Erkoflex (2mm EVA, Erkodent, Germany).

\section{SECTIONING THE UPPER ANTERIOR TEETH}

All practical work was carried out by one examiner. The upper anterior teeth on each study model (canine to canine) were marked along the facial axis of the clinical crown FACC line [4], with a thin pencil (size $0.3 \mathrm{~mm}$ ). The FACC line was located manually using electronic callipers accurate to $0.01 \mathrm{~mm}$ (Mitutoyo, Japan). A pencil line was placed down the centre of the labial surface to pass through 2 marks made halfway between the calliper widths at 2 different positions down the crown length. A line was then drawn through these points to meet with the gingival margin in one direction and the incisal edge in the other direction (Fig. 1). The teeth were individually separated using a very thin diamond disc (Microslice II precision slicing machine, Malvern Instrument, England) with a round annular blade having the cutting surface on the inner edge. The blade was approximately $17.5 \mathrm{~cm}$ in diameter and $0.3 \mathrm{~mm}$ thick. Each tooth was mounted on a glass slide using red wax and yellow sticky wax. The labial tooth surface was aligned parallel to the glass slide, so that the FACC line was perpendicular to the slide edge to aid alignment for cutting the tooth along this line. Information for later identification was added to each slide prior to cutting. The slides were placed on the platform beneath the cutting disc and adjusted such that the pencil line was parallel to the cutting edge of the blade. The platform of the machine was adjustable $(0.01 \mathrm{~mm}$ steps) facilitating precise position- ing of the slide. Red and green marker spots were used for identifying the mesial and distal portion of each sectioned tooth and included in subsequent imaging.

\section{IMAGE ANALYSIS SYSTEM}

A computerised image analysis system [5] was used to analyse the study models. A 32-bit digital camera (Kodak Nikon DCS 410, with a 1.5 mega pixel resolution in an array of $1012 \times 1524$ pixels, producing 4.6 MB TIF files) was attached to a copy stand (Kaiser, Germany) using an adjustable camera mount. The copy stand had a base marked with a grid to aid specimen relocation. The camera was connected to a computer (Viglen CX1 Dual processor, $2 \times 850 \mathrm{MH}_{2} \mathrm{CPU}$ 's, Viglen Ltd, UK) via an Adaptec 2940 SCSI card (KJP Ltd, UK). Light was provided by two white fluorescent tubes on the right and left side of the copy stand. Each light was adjustable in all three planes.

\section{ACQUISITION AND STORAGE OF IMAGES}

Images were displayed using Adobe Photoshop acquisition software (V5.02, Adobe Systems, Ltd, Europe) and viewed within ten seconds on the computer screen. Once acquired, each image was checked for quality and re-imaged if necessary. The images were saved as tagged image format files (TIFFs) as this format contains all of the original data. A permanent database was created of the original images.

\section{PROXIMAL SURFACE OF UPPER ANTERIOR TEETH}

Each tooth section was placed on a blue rubber base to provide consistent background contrast when imaged, and a steel rule was placed on the base adjacent to the tooth section for calibrating the image. All the sections were positioned with the same orientation to remove the need to rotate the images on screen later. Following acquisition each image 


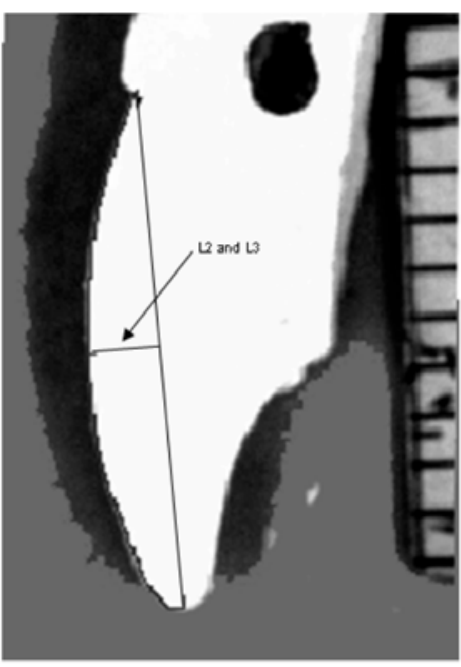

Md.point (L2) and most:prominent point

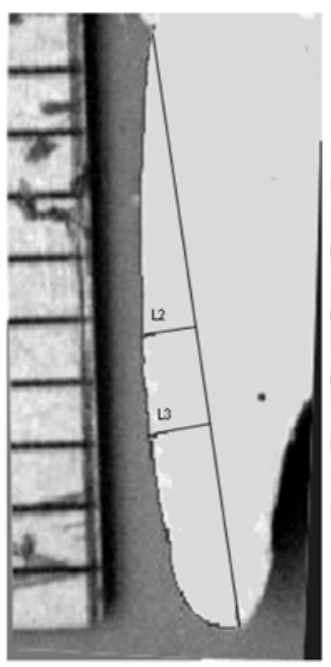

L3, the most.prominent poine

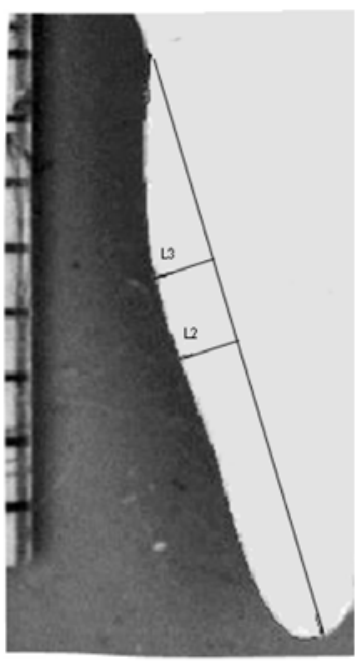

L3. the most-prominern poimt is gingival to the mid.

Fig. (2). Examples of the most-prominent point presenting coincident, incisal and gingival to the mid-point of the labial curve.

Table 1. Reliability of the Preparation of the Proximal View Slices $(\mathrm{N}=40)$

\begin{tabular}{|c|c|c|}
\hline Variable & Labial Curve & Proximal Line \\
\hline \hline Mean difference & $0.00 \mathrm{~mm}$ & $0.03 \mathrm{~mm}$ \\
\hline SD of differences & $0.44 \mathrm{~mm} \mathrm{~mm}$ \\
\hline SE of differences & $0.10 \mathrm{~mm}$ & $0.050 \mathrm{~mm}$ \\
\hline Repeatability coefficient & $0.86 \mathrm{~mm}$ & $0.43 \mathrm{~mm}$ \\
\hline ICCC & 0.94 & 0.95 \\
\hline
\end{tabular}

was viewed using "Adobe PhotoShop" and was re-imaged if required.

The perimeter of the labial curve was traced from the gingival margin to the incisal edge. A straight line connecting the gingival margin and the incisal edge called the proximal line was then drawn (Fig. 1). The distance (L2) from the proximal line to the labial curve at the mid point was then obtained using the 'length' option within the Image Pro Plus software (version 4, Media Cybernetics, UK). Similarly, the most prominent point of the labial curve to the proximal line was obtained by drawing a tangent parallel to the proximal line using the length option (L3). The point at which the tangent was the greatest length from the labial curve was the most prominent point. The vertical distance between L2 and L3 along the proximal line was determined (L4). L4 was measured and was either negative or positive in value, according to the position of the most prominent point being incisal or gingival respectively to the mid-point (Fig. 1).

\section{DATA ANALYSIS}

The reliability of the total procedure was calculated from 20 of the study models (10 male and 10 female randomly selected) and included duplicating study models, resectioning and re-imaging the cut sections. The labial curve (gingival margin to incisal tip along the labial edge of the section) and the proximal line were used to show that the mesial and distal portions of the teeth were reproducibly created and that either side could have been chosen. The mean difference, standard deviation of the difference, standard error of the difference and intra-operator repeatability coefficients were calculated as well as Fleiss [6] Intra-class Correlation Coefficient of Reliability (ICCC). Bland Altman plots were produced for all repeat measures to ensure no size/error relationships and to check for outliers and bias [7].

For L2, L3 and L4 forty cases were assessed for the experimental data including the mean value, standard deviation and range (minimum and maximum values). A negative L4 value signifies the most-prominent point is incisal to the mid-point, whereas a positive L4 values infers the mostprominent point is gingival to the mid-point (Fig. 2). The authors would also like to recognise the importance of further study assessing the shape of posterior teeth. These could not be considered here due to time constraints of the main author.

\section{RESULTS}

\section{Reliability}

Table 1 shows that comparison of measurement of the labial curve and the proximal line from both mesial and distal gave 'excellent repeatability' according to Donner and Eli- 
Table 2. Reliability of Slice Preparation and Measurement $(\mathrm{N}=40)$. Left and Right Teeth Combined (mm)

\begin{tabular}{|c|c|c|c|c|c|c|c|c|c|}
\hline \multirow[b]{2}{*}{ Variable } & \multicolumn{3}{|c|}{ Central Incisors } & \multicolumn{3}{|c|}{ Lateral Incisors } & \multicolumn{3}{|c|}{ Canines } \\
\hline & L2 & L3 & $\mathrm{L} 4$ & L2 & L3 & L4 & $\mathrm{L} 2$ & L3 & $\mathrm{L} 4$ \\
\hline Mean difference & 0.02 & 0.03 & 0.00 & 0.03 & 0.02 & 0.00 & 0.02 & 0.03 & 0.00 \\
\hline $\begin{array}{l}\text { SD of differ- } \\
\text { ences }\end{array}$ & 0.09 & 0.08 & 0.06 & 0.08 & 0.08 & 0.01 & 0.09 & 0.09 & 0.08 \\
\hline $\begin{array}{l}\text { SE of differ- } \\
\text { ences }\end{array}$ & 0.02 & 0.02 & 0.01 & 0.02 & 0.02 & 0.00 & 0.02 & 0.02 & 0.02 \\
\hline $\begin{array}{c}\text { Repeatability } \\
\text { coefficient }\end{array}$ & 0.18 & 0.16 & 0.12 & 0.16 & 0.16 & 0.02 & 0.18 & 0.18 & 0.16 \\
\hline ICCC & 0.93 & 0.93 & 0.98 & 0.83 & 0.81 & 0.99 & 0.95 & 0.95 & 0.99 \\
\hline
\end{tabular}

Table 3. Descriptive Statistics for L2, L3 and L4 for 40 Right and Left Upper Anterior Teeth (mm)

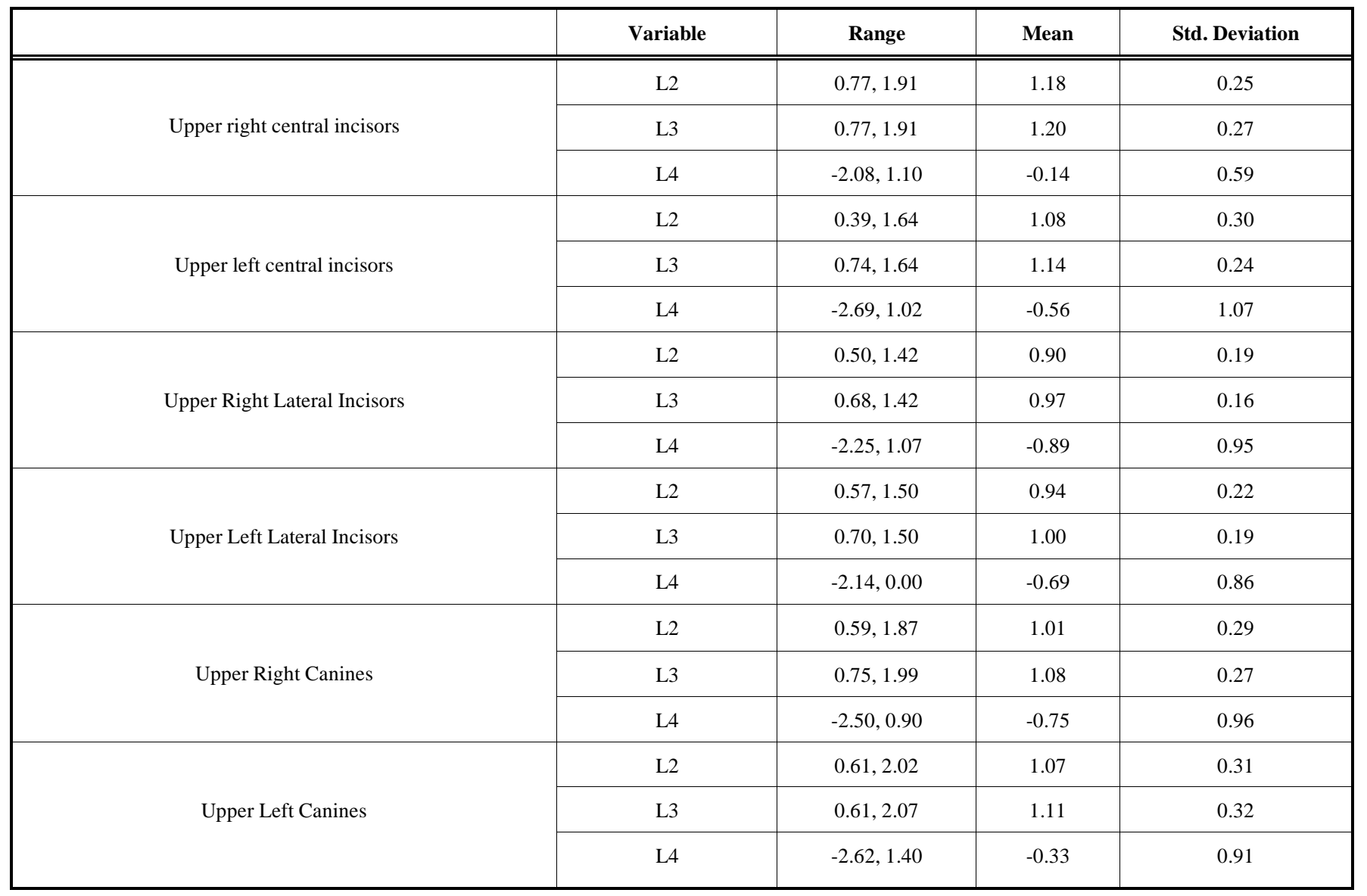

asziw [8] classification of Fleiss ICCC [6]. This indicates the model preparation, cutting and imaging and variable measurement was repeatable. This data also qualifies that either the mesial or distal slice could be used, with confidence and produce the same findings (Table 1). It was clear from the Bland Altman plots and the fact that all the mean differences were less than $1.96 \mathrm{x}$ Standard error that the method produced no significant bias.
Table 2 shows repeat measurements for variables L2, L3 and L4 for all three tooth types. Repeat measures were taken a week after the initial measurement. All the variable measurements produced 'excellent repeatability' with no significant bias found.

Tables 3 and $\mathbf{4}$ show the anterior labial curve is not flat (has a most-prominent point) and is often not symmetrically curved, as there are a high percentage of cases displaying a difference between the position of the mid-point and the 
Table 4. Percentage of Most-Prominent Point's Found Coincident, Incisal or Gingival to the Mid-Point's on Upper Anterior Teeth

\begin{tabular}{|c|c|c|c|c|}
\hline Tooth Type & Tooth Location & Coincident & Incisal & Gingival \\
\hline \hline \multirow{2}{*}{ Upper Central Incisors } & Right & $82.5 \%$ & $12.5 \%$ & $5.0 \%$ \\
\cline { 2 - 5 } & Left & $72.5 \%$ & $25.0 \%$ & $50.0 \%$ \\
\hline Upper Lateral Incisors & Right & $47.5 \%$ & $40.0 \%$ & $2.5 \%$ \\
\cline { 2 - 5 } & Left & $60.0 \%$ & $42.5 \%$ & $2.5 \%$ \\
\hline Upper Canines & Right & $75.0 \%$ & $20.0 \%$ & $5.0 \%$ \\
\cline { 2 - 5 }
\end{tabular}

most-prominent point. The most-prominent point on all tooth types was mainly incisal to the mid-point if it was not coincident with only a small percentage gingival to the midpoint. The upper lateral incisors showed the greatest number of instances where the most-prominent point was incisal, followed by the canines with the central incisors showing the greatest coincidence and therefore symmetry.

\section{DISCUSSION}

From Tables $\mathbf{1}$ and $\mathbf{2}$ it is clear that this method was repeatable and therefore a sound approach to assessing the curvature of upper anterior teeth from study models. All ICCC's were in the excellent range of reliability and the Bland Altman plots showed no significant bias and acceptable repeatability coefficients.

Previous research studies have investigated the variation of tooth morphology and its relationship to bracket positioning. Variation in labial tooth surface morphology affects the angle at which a bracket may be seated in relation to the facial axis of the clinical crown. It has been presumed, in respect of bracket placement, that the mid-points and mostprominent points are coincident on the labial surface of anterior teeth [4,9]. This study has shown, for the first time that these two points show coincidence at approximately $80 \%$ on central incisors reducing to approximately $50 \%$ on lateral incisors and canines. This means that on approximately $20 \%$ of central incisors and $50 \%$ of laterals and canines, brackets will be placed at the mid-point of the labial curve when it is not the most-prominent point. In this situation the labial curve is not symmetrical vertically about the mid-point such that the bracket will not sit in the preferred position parallel to the proximal line (facial axis of the clinical crown) as mentioned by Andrews [2]. This situation could introduce axial forces affecting the inclination of these teeth $\left(3^{\text {rd }}\right.$ order correction) and increase the need for extra final adjustment after initial alignment. Our data is in agreement with previous tooth morphology studies on labial surface variation [1015] but provides extra specific information regarding midand most-prominent point coincidence and location.

This study only considered class 1 relationships from patients requiring minor adjustments only to the lower dentition. The size and shape of a tooth will obviously affect the amount of torgue/ force required but the effect of each measurement variation would require a separate study. This paper and study discuss' the effect of the curvature of the tooth surface and therefore difference between the mid and most prominent points only.

\section{CONCLUSIONS}

This method of preparing proximal sections of upper anterior teeth from study models and there subsequent measurement by image analysis, has demonstrated a reliable way of assessing coincidence of mid- and most-prominent points on the labial surface of upper anterior teeth.

The assessment of mid- and most-prominent point location on the central incisor cases showed greatest symmetry with only $20 \%$ of cases having non coincident mid- and most-prominent points whilst lateral incisors and canines presented with approximately $50 \%$ non coincidence.

The, overall, high proportions of non-coincident examples found suggest that clinicians should be aware of individual variation and that this may possibly effect $3^{\text {rd }}$ order alignment.

\section{REFERENCES}

[1] Proffit WR. Contemporary Orthodontics $2^{\text {nd }}$ ed. St. Louis: CV Mosby Co. 1993.

[2] Andrews LF. The straight-wire appliance origin, controversy, commentary. J Clin Orthodont 1976; 10: 99-114.

[3] Balut N, Klapper L, Sandrik J, Bowman D. Variation in bracket placement in the pre-adjusted orthodontic appliance. Am J Orthodont 1992; 102: 62-7.

[4] Andrews LF. The six keys to normal occlusion. Am J Orthodont 1972; 62: 269-309.

[5] Brook AH, Smith RN, Elcock C, Al-Sharood MH, Shah AA, Karmo M. In The measurements of tooth morphology: development and validation of a new image analysis system. Mayhall JJ, Hakkinon T, Eds. Dental Morphology. Finland: Oalaunios Press 1999; pp. 380-387.

[6] Fleiss JL. Reliability of measurement, the design and analysis of clinical experiments. New York: Wiley and Sons, Inc. 1986; pp. 132.

[7] Bland JM, Altman DG. Statistical method for assessing agreement: two methods of clinical measurement. Lancet 1986; 1: 307-10.

[8] Donner A, Eliasziw M. Sample size requirements for reliability studies. Stat Med 1987; 6: 441-8.

[9] Andrews L, Straight-wire F. The Concept and Appliance. San Diego: Wells LA 1989.

[10] Taylor RMS. Variation in form of human teeth. An anthropologic and forensic study of maxillary incisors. J Dent Res 1969; 48: 5-16.

[11] Thruow RC. Edgewise Orthodont. $3^{\text {rd }}$ ed. St. Louis: CV Mosby 1972.

[12] Meyer M, Nelson G. Pre-adjusted edgewise appliance theory and practice. Am J Orthodont 1978; 73: 485-98. 
[13] Germane N, Bentley B, Isaacson JR, Rever JH. The morphology of the canines in relation to pre-adjusted appliances. Am J Orthodont 1986; 60(1): 49-54.

[14] Taylor NG, Cook PA. The reliability of positioning pre-adjusted Brackets: an in vitro Study. Brit J Orthodont 1992; 19(1): 25-34.
[15] Van Loenen M, Degrieck G, De Pauw G, Dermaut L. Anterior tooth morphology and its effect on torque. Eur J Orthodont 2005; 27: $258-62$

Received: September 26, 2008

Revised: November 06, 2008

Accepted: June 08, 2009

(C) Smith et al.; Licensee Bentham Open.

This is an open access article licensed under the terms of the Creative Commons Attribution Non-Commercial License (http://creativecommons.org/licenses/by-nc/3.0/) which permits unrestricted, non-commercial use, distribution and reproduction in any medium, provided the work is properly cited. 